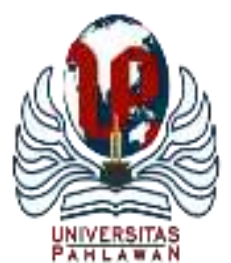

Edukatif : Jurnal Ilmu Pendidikan Volume 4 Nomor 1 Tahun 2022 Halm 1274 - 1280

EDUKATIF: JURNAL ILMU PENDIDIKAN

Research \& Learning in Education

https://edukatif.org/index.php/edukatif/index

\title{
Social Movement Berbasis Islam (Studi Tentang Gerakan Sosial Melawan Degradasi Moral di Era Pendidikan Berbasis Digital pada Remaja)
}

\author{
Bambang Trisno ${ }^{1 凶}$, Iswantir $\mathbf{M}^{2}$ \\ Institut Agama Islam Negeri (IAIN) Bukittinggi, Indonesia ${ }^{1,2}$ \\ E-mail : bambangtrisno@iainbukittinggi.ac.id ${ }^{1}$, iswantir@iainbukittinggi.ac.id $^{2}$
}

\begin{abstract}
Abstrak
Perkembangan peradaban manusia saat ini banyak menimbulkan perubahan, mulai dari politik sampai kepada sosial budaya dalam masyarakat. Hal ini juga yang sering memunculkan konflik antara masyarakat dengan negara. Indonesia sebagai Negara berkembang sangat merasakan perubahan-perubahan tersebut. Hal ini memunculkan kekhawatiran pada orang tua, guru para ulama dan warga yang risau para remaja tercebur ke dunia yang bisa merusak mental dan moral mereka. Salah satu daerah yang sangat merasakan hal itu adalah masayarakat Kota Bukittinggi, adanya kasus pembunuhan teman karena persoalan asamara, tertangkapnya para remaja kubang putih sebagai pengguna narkoba and masih banyak kerusakan moral yang lainnya. Jika hal ini terus dibiarkan dirisaukan semakin rendahnya moral pergaulan dikalangan remaja di kota Bukittinggi. Penelitian ini bertujuan untuk menganalisis aksi gerakan social berbasis Islam untuk melawan degradasi moral di Bukittinggi, dengan metode kualitatif deskriftif. Hasil penelitian menunjukkan belum maksimalnya aksi gerakan sosial berbasis islam di Kota Bukittinggi yang dilakukan oleh para tokoh ulama.
\end{abstract}

Kata Kunci: Gerakan sosial, Degradasi Moral, Remaja

\begin{abstract}
The development of human civilization today causes many changes, ranging from politics to social culture in society. This also often leads to conflict between the community and the state. Indonesia as a developing country really feels these changes. This raises concern for parents, teachers, scholars and residents who are worried that teenagers will fall into a world that can damage their mental and moral values. One area that really feels this is the people of Bukittinggi City, the case of the murder of a friend because of the affair, the arrest of white beetle teenagers as drug users and many other moral damages. If this is allowed to continue to worry about the lower morale of association among teenagers in the city of Bukittinggi. This study aims to analyze the actions of Islamic-based social movements to fight moral degradation in Bukittinggi. The results of the study indicate that the actions of Islamic-based social movements in Bukittinggi City have not been maximally carried out by ulama figures.
\end{abstract}

Keywords: Social movement, Moral Degradation, Youth

Copyright (c) 2022 Bambang Trisno, Iswantir M

$\square$ Corresponding author

Email : bambangtrisno@iainbukittinggi.ac.id

DOI $\quad$ : https://doi.org/10.31004/edukatif.v4i1.2117

ISSN 2656-8063 (Media Cetak)

ISSN 2656-8071 (Media Online) 
1275 Social Movement Berbasis Islam (Studi Tentang Gerakan Sosial Melawan Degradasi Moral di Era Pendidikan Berbasis Digital pada Remaja) - Bambang Trisno, Iswantir M

DOI: https://doi.org/10.31004/edukatif.v4i1.2117

\section{PENDAHULUAN}

Allah berfirman di dalam Al-quran dirikanlah salat dan ajaklah manusia berbuat yang makruf dan cegahlah (mereka) dari yang mugkar. Demikian bunyi firman Allah di dalam Al-quran yang memerintahkan umat manusia agar selalu berbuat baik dan mencegah perbuatan buruk. Manusia hakikatnya adalah suci dan baik. Seperti ungkapan seorang filsuf dan pencetus sosiologi modern Emile Durkheim berpandangan bahwa "there is no society without morality, but the morality of an underdeveloped society is not ours". Tidak ada masyarakat tanpa moralitas, akan tetapi moralitas masyarakat terbelakang bukanlah milik kita. Sederhananya adalah masyarakat itu bermoral, hakikatnya masyarakat itu terdiri dari masnusia-manusia yang baik. Jika ada manusia tidak bermoral itu bisa dikatakan bukan manusia karena itu bukan hakikat manusia. Lebih lanjut Durkheim menjelaskan moral adalah perilaku apa yang harus kita ambil pada saat dan sebelum bertindak itu ditetapkan oleh norma (Zuriah, 2015). Namun, perkembangan peradaban manusia saat ini banyak menimbulkan perubahan, mulai dari politik sampai kepada social budaya dalam masyarakat, seperti yang dikatakan (Setiawan, 2017) bahwa Teknologi digital masa kini yang semakin canggih menyebabkan terjadinya perubahan besar dunia. Hal ini juga yang sering memunculkan konflik antara masyarakat dengan negara.

Oleh karenanya moral menjadi dasar dalam kehidupan bermasyarakat, berbangsa, dan bernegara, dan pendidikan moral era modern ini sudah menjadi fenomena kemasyarakatan yang universal (Abidin, 2021). Indonesia sebagai negara berkembang sangat merasakan perubahan-perubahan tersebut. Perkembangan peradaban itu terlihat dengan adanya sikap hedonisme, konsumerisme masyarakat terhadap kecanggihan teknologi dan alat komunikasi yang salah satunya adalah Handphone (HP). Ditambah lagi pada era sekarang adanya kebijakan pemerintah pusat sampai kepada pemerintah daerah termasuk kota Bukittinggi yang mengijinkan para remaja untuk menggunakan HP sebagai alat untuk proses pembelajaran di rumah. Meskipun itu sangat membantu para remaja dalam belajar namun hal ini juga berdampak negatif bagi moral remaja dan mendapat keluhan juga dari para orang tua, guru bahkan para ulama. Salah satu bentuk keluhan ini sering disampaikan oleh para ulama dalam ceramahnya dulu dilarang membawa HP ke sekolah, sekarang wajib menggunakan HP. Hal ini menunjukkan hanpgone bukan lagi sekedar alat komunikasi (Laka, 2020),tapi juga sebagai alat untuk pembelajaran.

Hal ini memunculkan kekhawatiran pada orang tua, guru para ulama dan warga yang risau para remaja tercebur ke dunia yang bisa merusak mental dan moral mereka. Salah satu bentuk perlawanan masayarakat Bukittinggi terhadap penggunaan Teknologi diera digital ini adalah Bukittinggi yang terkenal dengan mottonya adat basandi sarak sarak basandi kitabullah (Yohanis, 2020) bisa pudar akibat terjadinya degradasi moral serta kenakalan para remaja. Berdasarkan pemantauan awal peneliti baru-baru ini pada bulan Februari 2021 lalu terjadi perkelahian yang dilakukan oleh dua orang pelajar di salah satu sekolah Bukittinggi terhadap temannya hingga salah satunya tewas. Persoalan itu dipicu oleh hal sepele yaitu persoalan asmara (Sikumbang, 2021). pada bulan yang sama tiga orang anak muda Kubang Putih Kota Bukittinggi ditangkap polisi karena diduga memakai obat-obatan terlarang sejenis narkoba (Safarud, 2021).

Jika hal ini terus dibiarkan dirsaukan semakin rendahnya moral pergaulan dikalangan remaja di kota Bukittinggi. Maka tidak salah apa yang diputuskan oleh MUI Kota Bukittinggi yang membuka kembali aktifitas ibadah di masjid dan mushallah dengan tetap memperhatikan protocol kesehatan (Alfatah, 2021). Karena bisa dikatakan degradasi moral yang terjadi di kalangan remaja saat ini, erat kaitannya dengan kemajuan teknologi dan kebijakan pemerintah serta kurangnya penanaman nilai-nilai agmaa kepada para reamaja. Dengan demikian sangat diperlukan sumbangsi daripada masayarakat dan tokoh agama untuk melakukan gerakan sosial di Kota Bukittinggi secara komprehensif dan berkelanjutan. Kiranya inilah yang menjadi dasar peneliti untuk melakukan penelitian ini. 
1276 Social Movement Berbasis Islam (Studi Tentang Gerakan Sosial Melawan Degradasi Moral di Era Pendidikan Berbasis Digital pada Remaja) - Bambang Trisno, Iswantir M

DOI: https://doi.org/10.31004/edukatif.v4i1.2117

\section{METODE PENELITIAN}

Metode yang digunakan dalam penelitian ini adalah melalui pendekatan kualitatif dengan metode deskriftif (Prasanti, 2018). Metode kualitatif dengan maksud mencari dan mengumpulkan data terhadap suatu masalah dengan menggunakan metode-metode yang dapat dibuktikan oleh seorang peneliti secara ilmiah. Menurut (Fadli, 2021) penelitian kualiatatif bertujuan untuk mendapatkan pemahaman yang mendalan mengenai masalah-masalah manusia dan sosial, bukan mendeskripsikan bagian permukaan dari sebuah realitas sebagaimana dilakukan penelitian kuantitatif dengan positivismenya. Karena peneliti menginterpretasikan bagaimana subjek memperoleh makna dari lingkungan sekeliling, dan bagaimana makna tersebut mempengaruhi perilaku mereka. Penelitian dilakukan dalam latar (setting) yang alamiah (naturalistic) bukan hasil perlakuan (treatmen) atau manipulasi variable yang dilibatkan. Secara garis besar, sistematika penulisan ini lebih bersifat narasi yang mengumpulkan pendapat para ahli, jurnal, buku serta tulisan yang dimuat di internet (Permana \& Puspitaningsih, 2021) terkait dengan gerakan social berbasis islam dalam melawan degradasi moral pada remaja Bukittinggi.

\section{HASIL DAN PEMBAHASAN PENELITIAN}

Moral adalah suatu hal yang tidak terpisahkan dari eksistensi keberadaan manusia (Pratama, 2021). Dan pendidikan merupakan akar pembentukan dan pengembangan moral pada manusia itu sendiri. Sejatinya pendidikan moral sudah dilakukan di sekolah melalui pelajaran PPKn dan berbasis Islam melalui Pelajaran Pendidikan Agama Islam (Ibda, 2012). Berkaitan dengan moral para remaja di bukittinggi, hasil wawancara peneliti dengan Ketua Dewan Dakwah Kota Bukittinggi bapak Dr. Syaiful Amin. Ketika ditanya tentang tentang kemerosotan moral para remaja kota Bukittinggi di era digital ini (contoh: kasus seorang pelajar membunuh temannya karena pacar, tertangkapnya remaja kubang putih sebagai pengguna narkoba, dan kemaksiatan lainnya yang terjadi di kota bukittinggi oleh para remaja. Bapak Syaiful menjelaskan bahwa "Sebenarnya digital ibarat dua mata pisau yang bisa digunakan untuk memotong bawang bisa juga melukai kalau tidak hati hati menggunakannya. Artinya kita diharapkan dalam menggunakan pisau itu harus hati-hati kalau tidak ia akan melukai. Begitu juga digital, untuk itu remaja tidak bisa disalahkan begitu saja,yang dibutuhkan adalah kontrol dan arahan serta pendidikan, beserta contoh yang baik bagi anak. Berdasarkan pernyataan ini, degradasi moral yang terjadi bisa jadi disebabkan karena para remaja tidak dapat memanfaatkan digitalisasi dengan baik, sehingga kata melukai dalam pernyataan itu dapat diartikan merusak moral yang ada dalam diri para remaja Kota Bukittinggi itu sendiri.

Hal ini sejalan dengan pernyataan Bapak Fahmil Syamirin selaku Ketua IKADI Da'I Kota Bukittinggi yang mengatakan bahwa "Saya tidak mau mekambing hitamkan digital,karena digital itu adalah ibarat pisau bermata dua, bisa untuk kebaikan dan bisa untuk keburukan,bisa untuk memotong bawang bisa untuk melukai, artinya digital itu tergantung penggunaannya, seharusnya remaja diarahkan, di didik di beri tahu mana yang baik dan buruk, karena sebelum ada di gital ada juga kenakalan remaja yang penting bagi orang tua, tenaga pendidik dan masyarakat mendidik kepada arah yang lebih baik atau islami,terjadinya degaradasi itu karena tidak ada tauladan dan pendidik yang baik dari rumah dan,masyarakat". Poin yang beliau sampaikan adalah, era digitalisasi adalah suatu keharusan, seperti yang diungkapkan (Rahayu, 2019) Era digital merupakan suatu masa di mana sebagian besar masyarakat pada era tersebut menggunakan sistem digital dalam kehidupan sehari-harinya. Selain itu era digitalisasi merupakan tuntutan. Pada era revolusi industri 4.0 pendidikan dituntut untuk mengikuti perkembangan teknologi serta memanfaatkan teknologi informasi dan komunikasi sebagai fasilitas lebih dan serba canggih untuk memperlancar proses pembelajaran (Putriani \& Hudaidah, 2021).

Mengenai kenakalan remaja sebelum era digitalisasipun kenakalan remaja itu sudah ada. Khusus tentang degradasi moral remaja Bukittinggi lebih disebabkan oleh tidak adanya role of model atau tauladan 
1277 Social Movement Berbasis Islam (Studi Tentang Gerakan Sosial Melawan Degradasi Moral di Era Pendidikan Berbasis Digital pada Remaja) - Bambang Trisno, Iswantir M

DOI: https://doi.org/10.31004/edukatif.v4i1.2117

bagi para remaja. Tidak jauh berbdeda dengan dua tokoh diatas, Bapak Aidil Alfin MUI Kota Bukittinggipun mengamini bahwa "degradasi moral itu sudah ada sejak lama dan perlu segera kita atasi".

Lebih lanjut mengenai langkah apa yang sudah dilakukan oleh para tokoh di Kota Bukittinggi untuk mencegah dan mengurangi degradasi moral yang terjadi para remaja Bukittinggi. Bapak Syaiful Amin menagatakan bahwa "Saya rasa perlu pemberitahuan dan kontrol, langkah yang harus kita lakukan membina remaja dan memberikan program-program ke islaman dan hal-hal yang positif untuk masa depan mereka". Senada dengan itu Bapak fahmil Selakun ketua IKADI juga mengatakan "Saya lebih mengusulkan ada pembinaan remaja,pemuda di surau, masjid, dan di sekolah sekolah dengan program yang positif dan arah lebih baik ,dan megarahkan pada penggunaan digital secara sehat, sehingga mereka berhati hati menggunakan digital". Dan langkah nyata dijelaskan oleh bapak Aidil selaku Ketua MUI Kota Bukittinggi, yaitu dengan menjalankan program-program seperti mengaktifkan remaja masjid, melarang para remaja dan masayarakat Bukittinggi untuk merayakan hari pergantian tahun setiap tahunnya, serta melarang memperingati hari valentine day setap tanggal 14 Februari. Karena menurut beliau pada kegiatan-kegiatan tersebutlah moral para remaja akan menjadi rusak. Seperti yang kita ketahui Valendine day merupakan salah satu perayaan di seluruh dunia terutama dikalangan para remaja untuk mengungkapkan kasih sayang melalui ungkapan-ungkapan romantis melalui kartu ucapan dan dengan pemberian hadiah seperti bunga, cokelat, kue, boneka dan lainnya (Syam, 2007). Para ulama di kota Bukittinggi sepakat bahwa hal itu, baik perayaan malam tahun baru maupun valentine day bukan merupakan budaya Islam dan bertentangan dengan akidah Islam, sebagaimana firman Allah SWT "Dan janglah kamu megikuti apa yang kamu tidak mempunyai pengetahuan tentangnya. Sesungguhnya pendengaran, penglihatan, dan hati, semuanya itu akan diminta pertanggung jawabnya." (Surah Al-Isra : 36). Oleh karenanya Ikatan Dai Bukittinggi sudah menghimbau melalui untuk mengisi waktu liburan sekolah dan pergantian tahun baru para remaja seperti pada gambar berikut:

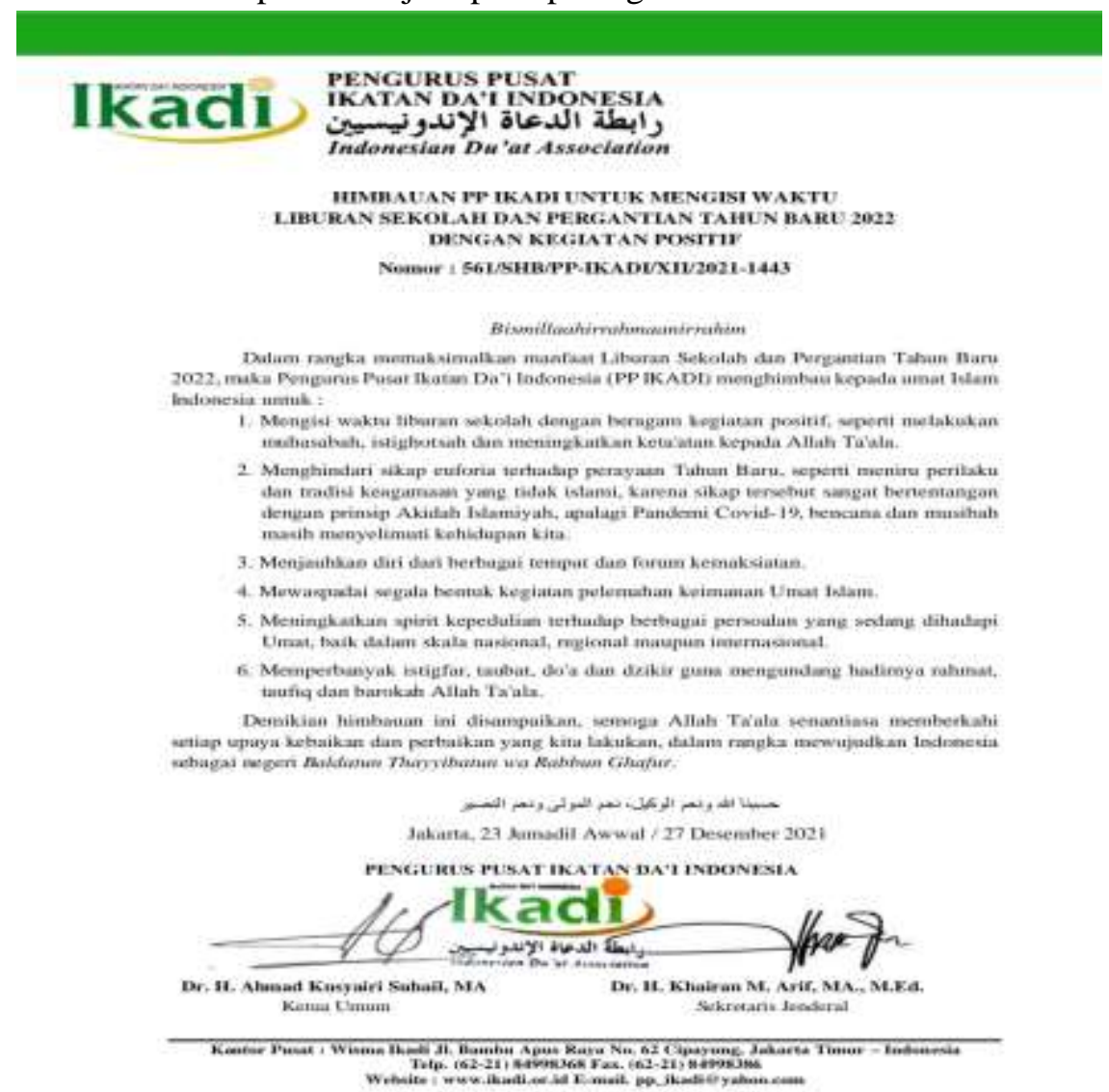

\section{Gambar Salah Satu Upaya IKADI Kota Bukittinggi}

Edukatif : Jurnal Ilmu Pendidikan Vol 4 No 1 Tahun 2022 p-ISSN 2656-8063 e-ISSN 2656-8071 
1278 Social Movement Berbasis Islam (Studi Tentang Gerakan Sosial Melawan Degradasi Moral di Era Pendidikan Berbasis Digital pada Remaja) - Bambang Trisno, Iswantir M

DOI: https://doi.org/10.31004/edukatif.v4i1.2117

Adapun dampak dari langkah yang sudah dilakukan, ketua Dewan dakwah dan Ketua Ikadi Bukittinggi sepakat mengatakan "Kita belum ada survei,tapi yang jelas remaja yang terbina aqidah dan agamanya biasanya akan menjadi remaja yang baik dan sukses dalam belajarnya". Harapan ini sejalan dengan yang dikatakan (Sobri, 2021) bahwa untuk menjadi remaja yang baik perlu internalisasi nilai-nilai moral. Internalisasi nilai-nilai moral yang dapat dilakukan antara lain: membaca Al-Qur'an, shalat dhuha, dan Shalat Dhuhur berjama'ah. Adapun kegiatan mingguan yaitu : Membaca Asmaul Husna, Jum'at beramal. Dan menurut pengakuan Pak Aidil hal ini sudah dilakukan di sekolah-sekolah dan sudah disosialisasikan juga di masyarakat, terutama kalangan remaja. Kegiatan tersebut diharapkan dilakukan secara intensif dan berkelanjutan agar bias membentuk moral yang baik, terutama sholat dan membaca Al-Quran. Al-Qur'an merupakan pendidikan mendasar yang harus dimiliki oleh siswa sebab pengetahuan dalam membentuk moral dan perilaku manusia yang sesuai norma sudah dijelaskan di dalam Al-Qur'an (Ardiani et al., 2020).

Lebih lanjut Bapak Aidil menjelaskan kegiatan ini sebetulnya sudah berjalan dengan baik dan sudah dilaksanakan sejak tahun 2016, namun belakangan ini kurang mendapat dukungan dari berbagai pihak, terutama masalah pendaanaan, terlebih karena kasus Corona sejak 3 tahun terakhir, para ulama sulit menjalankan program-program yang sudah disebutkan tadi (larangan perayaan valentine day dan larangan merayakan malam pergantian tahun baru masehi). Oleh karenanya MUI makmaksimalkan pada kegiatan ceramah di bulan ramadhan dan wirid mingguan remaja di masjid masjid saja yang tidak memerlukan banyak dana.

Berdaasarkan hasil penelitian dapat dijelaskan bahwa sudah adanya gerakan social berbasis Islam untuk mengurangi degradasi moral yang terjadi di Kota Bukittinggi era Digitalisasi ini. Hal ini bias dilihat dari program-program yang dilakukan oleh berbagai pihak sudah memenuhi karakteristik dari gerakan sosial. Adapun karakteristik gerakan sosial pada umumnya seperti yang diungkapakan oleh (Haris et al., 2019) yaitu: Pertama, terdiri dari sejumlah orang. Seperti yang kita temui, untuk mengurangi degradasi moral remaja bukittinggi sudah dilakukan secara bersama-sama, baik sekolah, Dewan Dakwah Bukittinggi, IKADI Bukittinggi maupun MUI Bukittinggi. Kedua, mempunyai tujuan tertentu, Dari program yang dibuat, jelas tujuannya adalah satu yaitu cerdas menggunakan teknologi agar moral tetap terjaga, sehingga bias mengurangi kemerosotan moral pada remaja Bukittinggi. Ketiga bersifat terorganisir. Program yang dibuat baik IKADI dan MUI Bukittinggi bukanlah program yang spontanitas, akan tetapi program yang terstruktur dan berkelanjutan, seperti yang diungkapkan oleh Ketua MUI diatas tadi, larangan merayakan valentine day dan malam tahun baru itu sudah dilakukan sejak tahun 2016 hingga sekarang. Dan yang keempat didukung dana yang cukup. Bagaimanapun dan apapun namanya kegiatan, pasti butuh dana seperti yang diungkapkan oleh (Yuandi K. Timbul, 2013) bahwa dimana setiap aktivitas yang dijalankan oleh perusahaan pastinya memerlukan dana. Barangkali karakteristik ke empat ini yang belum optimal, dananya sudah ada seperti yang dijelaskan pak Aidil ketua MUI, namun masih kurang, ditambah lagi dengan adanya kasus Corona tiga tahun terakhir, makanya gerakan yang dilakukan menjadi kurang optimal.

\section{KESIMPULAN}

Melalui uraian hasil penelitian dan pembahasan diatas, dapat disimpulkan bahwa para tokoh ulama di kota Bukittinggi sudah berupaya melakukan gerakan social berbasis islami, dengan program-program atau kegiatan-kegiatan yang dilakukan seperti melarang para remaja merayakan valentine day, melarang merayakan malam pergantian tahun baru, dan membuat kegiatan remaja masjid di setiap minggunya, serta mengintenkan kegiatan ceramah di bulan Ramadahan. Nyatanya kegiatan tersebut belum maksimal dilaksanakan karena kurangnya dukungan moril dan materil baik dari pemerintah maupun masyarakat Bukitinggi. Ditambah lagi karena adanya pandemic Covid 19 sejak 2019 lalu mengakibatkan banyak kegiatan 
1279 Social Movement Berbasis Islam (Studi Tentang Gerakan Sosial Melawan Degradasi Moral di Era Pendidikan Berbasis Digital pada Remaja) - Bambang Trisno, Iswantir M

DOI: https://doi.org/10.31004/edukatif.v4i1.2117

tidak dapat dilaksanakan secara maksimal. Akibatnya kegiatan-kegiatan tersebut belum memberikan dampak yang berarti terhadap pencegahan degradasi moral pada remaja Kota Bukittinggi.

\section{UCAPAN TERIMA KASIH}

Ucapan Terimakasih penulis ucapkan kepada Ketua MUI Kota Bukittinggi, Ketua Dewan Dakwah Kota Bukittinggi, dan terimaksaih kepada Ketua IKADI Kota Bukittinggi. Selanjutnya terima kasih kepada seluruh warga kota Bukittinggi. Terakhir, penulis mengucapkan terimakasih kepada orang-orang yang sudah bekerjasama sehingga penelitian ini dapat diselesaikan dengan baik.

\section{DAFTAR PUSTAKA}

Abidin, M. (2021). Pendidikan Moral Dan Relevansinya Dengan Pendidikan Islam. 2, 57-66.

Alfatah. (2021). Mui Bukittinggi Aktifkan Kegiatan Ramadhan. Sumbar.Antarnews.Com. Https://Sumbar.Antaranews.Com/Berita/422474/Mui-Bukittinggi-Aktifkan-Kegiatan- Ramadhan-2021

Ardiani, R., Sosial, F. I., \& Makassar, U. N. (2020). Pengaruh Intensitas Membaca Al- Qur'an Tehadap Perilaku Keagamaan Mahasiswa Fakultas Ilmu Sosial Universitas Negeri Makassar. 143-168.

Fadli, M. R. (2021). Memahami Desain Metode Penelitian Kualitatif. Humanika, 21(1), 33-54. Https://Doi.Org/10.21831/Hum.V21i1.38075

Haris, A., Ab Rahman, A. Bin, \& Wan Ahmad, W. I. (2019). Mengenal Gerakan Sosial Dalam Perspektif Ilmu Sosial. Hasanuddin Journal Of Sociology, 1(1), 15-24. Https://Doi.Org/10.31947/Hjs.V1i1.6930

Ibda, F. (2012). Pendidikan Moral Anak Melalui Pengajaran Bidang Studi Ppkn Dan Pendidikan Agama. Jurnal Ilmiah Didaktika, 12(2), 338-347. Https://Doi.Org/10.22373/Jid.V12i2.457

Laka, B. M. (2020). Dampak Penggunaan Handphone Terhadap Perilaku Belajar Peserta Didik Di Sma Yayasan Sub Byaki Fyadi Kabupaten Biak Numfor. Pedagogika: Jurnal Pedagogika Dan Dinamika Pendidikan, 6(2), 58-78. Https://Doi.Org/10.30598/Pedagogikavol6issue2page58-78

Permana, T., \& Puspitaningsih, A. (2021). Studi Ekonomi Digital Di Indonesia. 4(2), 161-170.

Prasanti, D. (2018). Penggunaan Media Komunikasi Bagi Remaja Perempuan Dalam Pencarian Informasi Kesehatan. Lontar: Jurnal Ilmu Komunikasi, 6(1), 13-21. Https://Doi.Org/10.30656/Lontar.V6i1.645

Pratama, D. (2021). Profesionalitas Guru Melalui Pendekatan Empat Pilar Pendidikan Dalam Mengembangkan Nilai-Nilai Karakter Siswa. 1(2), 126-139. Https://EJournal.Upr.Ac.Id/Index.Php/Parislangkis

Putriani, J. D., \& Hudaidah, H. (2021). Penerapan Pendidikan Indonesia Di Era Revolusi Industri 4.0. Edukatif: $\quad$ Jurnal Ilmu Pendidikan, $\quad 3(3), \quad 838$. Https://Edukatif.Org/Index.Php/Edukatif/Article/View/407

Rahayu, P. (2019). Pengaruh Era Digital Terhadap Perkembangan Bahasa Anak. Al-Fathin: Jurnal Bahasa Dan Sastra Arab, 2(1), 47. Https://Doi.Org/10.32332/Al-Fathin.V2i2.1423

Safarud, L. (2021). Polres Bukittinggi Tangkap Tiga Remaja Diduga Terlibat Kasus Narkoba. Www.Antaranews.Com. Https://Www.Antaranews.Com/Berita/2012190/Polres-Bukittinggi-TangkapTiga-Remaja-Diduga-Terlibat-Kasus-Narkoba

Setiawan, W. (2017). Era Digital Dan Tantangannya. Seminar Nasional Pendidikan, 1-9.

Sikumbang, W. (2021). Pelajar Tewas Usai Berkelahi Rebutan Pacar, Keluarga Dan Teman-Teman Kehilangan. Sumbar.Inews.Id. Https://Sumbar.Inews.Id/Berita/Pelajar-Tewas-Usai-Berkelahi-RebutanPacar-Keluarga-Dan-Teman-Sangat-Kehilangan. 
1280 Social Movement Berbasis Islam (Studi Tentang Gerakan Sosial Melawan Degradasi Moral di Era Pendidikan Berbasis Digital pada Remaja) - Bambang Trisno, Iswantir M

DOI: https://doi.org/10.31004/edukatif.v4i1.2117

Sobri, S. (2021). Strategi Guru Pendidikan Agama Islam (Pai) Dalam Internalisasi Nilai-Nilai Moral Di Sekolah Dasar. Edukatif: Jurnal Ilmu Pendidikan, 3(4), 2313-2320. Https://Edukatif.Org/Index.Php/Edukatif/Article/View/900

Syam, E. (2007). Valentine Day: Hegemoni Budaya Dan Kapitalis. 3(2), 1-65.

Yohanis. (2020). Pembinaan Nilai - Nilai Adat Basandi Syarak, Syarak Basandi Kitabullah Oleh Ninik Mamak Terhadap Anak Kemenakan Di Kenagarian Situjuah Gadang Kec Limo Nagari Kab.Lima Puluh Kota. 2(2), 112-117.

Yuandi K. Timbul. (2013). Perputaran Modal Kerja Dalam Mengukur Tingkat Profitabilitas Pada. Jurnal Emba, 1(4), 138-155.

Zuriah, N. (2015). Pendidikan Moral Dan Budi Pekerti Dalam Perspektif Perubahan. Bumi Aksara. 